\title{
Lastik üretiminden kaynaklanan yüzey aktif madde içeren atık suların koagülasyon bazlı arıtma alternatiflerinin PROMETHEE yaklaşımı ile değerlendirilmesi
}

\section{Evaluation of coagulation based treatment alternatives of wastewater containing surfactant from tire manufacturing by PROMETHEE approach}

\author{
Elif Durna ${ }^{1, *}$ (D), Nevim Genç ${ }^{1}$ (D) \\ ${ }^{I}$ Kocaeli Üniversitesi, Çevre Mühendisliği Bölümü, 41000, Kocaeli, Türkiye
}

\section{Özet}

Bu çalışmada, araç lastiği üretim prosesinde preslenen hammadde hamurunun birbirine yapışmasını engellemek için kullanılan yüzey aktif madde içeren atık suyun, konvansiyonel koagülasyon ve mikrodalga oksidasyonu destekli elektrokoagülasyon prosesleri ile arttım incelenmistir. Prosesler Taguchi deney tasarımı yöntemi (L8) ile maksimum kimyasal oksijen ihtiyacı giderimini sağlayacak biçimde optimize edilmiştir. Pareto analizi ile mikrodalga oksidasyonu destekli elektrokoagülasyon prosesinde en etkili parametrenin mikrodalga süresi, konvansiyonel koagülasyon prosesinde ise $\mathrm{FeCl}_{3} .7 \mathrm{H}_{2} \mathrm{O}$ dozu olduğu bulunmuștur. Varyans analizi ile iki proses için de belirlenen modellerin kimyasal oksijen ihtiyacı giderimini açılamada anlamlı olduğu belirlenmistir. Optimum deneysel kosullardaki kimyasal oksijen ihtiyac giderimi, kimyasal çamur üretimi, işletme maliyeti ve proseslerin tercih edilebilirlik seviyeleri dikkate alınarak, çok kriterli karar verme süreçlerinden olan PROMETHEE yöntemi ile en uygun proses mikrodalga oksidasyonu destekli elektrokoagülasyon olarak belirlenmiştir. Mikrodalga oksidasyonu destekli elektrokoagülasyon prosesinde optimum sartlarda kimyasal oksijen ihtiyact giderim verimi, çamur miktarl ve işletim maliyetleri strasıyla \% 66.9, $6.27 \mathrm{~g} / \mathrm{L}$ ve $1.195 € / \mathrm{L}$ olarak bulunmustur. Prosesinin seçiminde kimyasal oksijen ihtiyact giderim verimi ve çamur miktar kriterlerinin pozitif yönde etki ettikleri belirlenmistir.

Anahtar kelimeler: Kimyasal koagülasyon, Mikrodalga Elektrokoagülasyon, Pareto analizi, PROMETHEE

\section{Giriș}

Sabun ve deterjanlar, yüzey aktif maddeler (ticari deterjanlar da genellikle \%10-30 yüzey aktif madde içerir), polifosfat tuzları ve ağartıcılar içeren formüle edilmiş ürünlerdir. Yüzey aktif maddeler, elektrolitik ayrışma özelliklerine göre sinıflandırılmaktadır. Burada hidrofilik polar grubun tabiatı, anyonik, katyonik, noniyonik ve amfoterik, belirleyici unsurdur. Anyonik yüzey aktif maddeler sulu çözeltide negatif yüklenmiş yüzey aktif madde üretir, genellikle sülfat, karboksilat veya sülfonat gruplarından türer. Katyonik yüzey aktif maddeler ise çözelti içinde pozitif yüklü yüzey aktif madde üretirler, başlica aminler ve türevleri ile quaternary amonyum tuzları gibi quaternary azot bileşiklerdir. Kötü temizleme özelliğinden dolayı deterjan olarak çok az kullanılırlar. Noniyonik yüzey aktif maddeler başlıca karboksilik asit amidleri ve esterlerdir (alkoksik olmuş alkoller). Noniyonik yüzey aktif maddelerde hidrofilik ve hidrofobik gruplar organiktir, amfoterik yüzey

\begin{abstract}
In this study, the treatment of wastewater containing surfactant used to prevent the sticking of the raw material pulp pressed in the tire production process, with conventional coagulation and microwave oxidation supported electrocoagulation processes was investigated. The processes were optimized to ensure maximum chemical oxygen demand removal by the Taguchi experimental design method (L8). With Pareto analysis, it was found that the most effective parameter in microwave oxidation-supported electrocoagulation processes is microwave duration while the most effective parameter in the conventional coagulation process was $\mathrm{FeCl}_{3} .7 \mathrm{H}_{2} \mathrm{O}$ dose. Analysis of variance found that the models determined for both processes were significant in explaining chemical oxygen demand removal. The appropriate process has been determined as the microwave oxidation-supported electrocoagulation, with the PROMETHEE method considering the optimum experimental conditions, chemical oxygen demand removal, chemical sludge production, operating cost and the preferability criteria of the processes. In microwave oxidation-supported electrocoagulation process, under optimum conditions, chemical oxygen demand removal efficiency, the amount of sludge production and operating costs were found as $66.9 \%, 6.27 \mathrm{~g} / \mathrm{L}$ and $1.195 € / \mathrm{L}$ respectively. It was determined that the criteria of chemical oxygen demand removal efficiency and sludge amount had a positive effect on the selection of the process.
\end{abstract}

Keywords: Chemical coagulation, Microwave, Electrocoagulation, Pareto analysis, PROMETHEE.

aktif maddeler ise sistemin pH'sına bağlı olarak sulu çözeltide hem anyonik hem de katyonik özellik gösterirler. $\mathrm{Bu}$ bileşiklerin esas tipi, lineer alkan sülfonatların analoglarıdır. Yüzey aktif maddeler, doğal sularda $1 \mathrm{mg} / \mathrm{L}$ gibi düşük derişimlerde bile köpürme problemlerine sebep olur, ancak insanlara bu derişim toksik değlidir [1]. Toksisite genellikle deterjanların türüne bağlıdır. Genel olarak noniyonik bileşiklerin daha az toksik olduğu, anyonik olanların ise çok toksik olduğu kabul edilir [2]. Katyonik yüzey aktif maddelerin toksisitesi ise anyoniklerden yüksektir [3].

Atık su arıtım ünitelerinde yüzey aktif maddeler, köpük oluşturması, lipofilik grupları solubilize etmesi, sıvının yüzey gerilimini veya katı/sıv1 ara yüzey gerilimini etkilemesi suretiyle ince partiküllerin stabilizasyonuna sebep olmaları nedeniyle fizikokimyasal veya biyolojik arıtım ünitelerinde problemlere neden olurlar. Noniyonik deterjanlar özellikle karakteristik özelliklerinden dolayı

\footnotetext{
* Sorumlu yazar / Corresponding author, e-posta / e-mail: elif.durna@ kocaeli.edu.tr(E. Durna)

Geliș / Recieved: 13.06.2020 Kabul / Accepted: 25.11.2020 Yayımlanma / Published: 15.01.2021

doi: $10.28948 /$ ngmuh. 7523
} 
geniş ölçüde kabul görmüştür, çünkü deterjanın formülasyonunda fosfat veya kostik dolgu malzemesine gereksinim duyulmamaktadır. Noniyonik yüzey aktif maddelerin iyonik yüzey aktif maddelere göre en önemli dezavantajı biyo-bozunurluk derecesinin nispeten düşük olmasıdır. Bu yüzden heterodisperse noniyonik yüzey aktif maddelerin gideriminde adsorpsiyon prosesi önemli bir yer tutmaktadir [1].

Atık sudan yüzey aktif madde giderimi için fizikselkimyasal [4-7], biyolojik [8-10], membran proses [11] ve ileri oksidasyon $[4,12,13]$ gibi çeşitli arıtım metotları kullanılmaktadır. Ticari ölçekteki uygulamalarda etkili, ekonomik ve çevre dostu olması bakımından adsorpsiyon prosesi oldukça tercih edilmektedir. Birçok teknik ile kıyaslandığında adsorpsiyon prosesi ile yüzey aktif maddelerin arıtımı çok iyi performans göstermektedir. Adsorpsiyon prosesi için çeşitli maddeler geliştirilmiştir. Aktif karbon en uygun adsorbenttir, ancak sentezlenmesi oldukça pahalı ve rejenere edilmesi de oldukça güçtür. $\mathrm{Bu}$ nedenle sürdürülebilir, çevreci, ekonomik ve yüksek verime sahip adsorbentlerin geliştirilmesine ihtiyaç duyulmaktadır [7].

Bunun yanı sira en yaygın uygulanan proseslerden olan koagülasyon-flokülasyon prosesinin ekonomik olduğu, işletiminin kolay ve enerji tüketiminin az olduğu ifade edilmektedir. Ancak bu proseste kullanılan ticari kimyasal koagülantların insan sağlığını ve çevreyi olumsuz etkilediği bilinmektedir [11]. Deterjan gideriminde koagülasyon prosesinin etkili olduğu kanıtlanmıştır. Ticari koagülantlar ve polielektrolitlerin kullanımı ile \%50'ye yakın anyonik deterjan giderimi elde edilmiştir [2].

Yüzey aktif maddelerin parçalanabilirliği düşük olduğu için konvansiyonel arıtım üniteleri ile giderimi güçtür. Genellikle arıtma çamurlarında birikerek, arıtma çamurlarının tarımsal kaynaklı kullanımını sınırlamaktadır. Evsel atık sularda yüzey aktif maddelein konsantrasyonları 1-10 mg/L arasında değişebilmektedir. yüzey aktif madde üretim endüstrisinde ise bu değer $300 \mathrm{mg} / \mathrm{L}$ ye kadar ulaşabilmektedir [15]. Evsel atık su arıtım ünitelerinde, evsel atık sulardaki yüzey aktif maddelerin derişimi 1-3 mg/L ye kadar düşebilmektedir, fakat bu durum çamurda önemli miktarda yüzey aktif madde birikimine sebep olmaktadır [16]. Yüzey aktif maddelerin biyoparçalanabilirliği literatürde anyonik $>$ noniyonik $>$ katyonik şeklinde sıralanmıştır [17].

Yüzey aktif maddeler biyolojik yaşam üzerinde olumsuz etkilere sebep olur. Biyolojik ve kimyasal arıtma tesislerinde de suyun yüzey gerilimini azalttıklarından dolayı suda bulunan partiküler maddelerin çökelmesini engelleyerek süspansiyon halinde suyun yüzeyinde kalmasına neden olurlar.

Yüzey aktif maddeler günlük yaşamda genellikle çeşitli yüzeylerden kiri uzaklaştırma özellikleri nedeni ile kullanılmaktadır. Birçok endüstriyel uygulamada farklı amaçlar için de kullanılmaktadır. Bu çalışmada araç lastiği üretim prosesinde preslenmiş hammadde hamurunun birbirine yapışmasının engellenmesinde kullanılan yüzey aktif madde içeren atık suyun arıtımı çalışılmıştır.
Araç lastiği, çok çeşitli hammaddelerin kullanımı ile oluşan ileri bir üründür. Otomobil lastiği ağırlıklı olarak \%47 kauçuk, \%21.5 karbon siyahı, \%16.5 metal, \%7.5 katk1 malzemesi ve \%5.5 tekstil malzemesi içerir. Üretim prosesinde lastiği oluşturan hammaddelerin karışımı ile oluşan çiğ hamurun preslenip meskole olmasını ve istiflenirken birbirine yapışmasını önlemek için anyonik ve noniyonik bazlı yüzey aktif maddeler kullanılır. Kullanılan yüzey aktif maddeler tamamen sülfat edilmiş tabii yağlardan üretilmiş modifiye sabun esaslı olduğundan kauçuk hamuruna zarar vermez. Preslenmiş hamurun kapalı bir tank içindeki yüzey aktif maddeye daldırılması ile veya yüzey aktif maddenin hamura püskürtülmesi sureti ile uygulanmaktadır. Lastiğin yapısına zarar vermeyen ve preslenen lastiklerin birbirine yapışmasını engelleyen yüzey aktif maddeler lastik üretim sektöründe önemli bir kirlilik kaynağı oluşturmaktadır.

Lastik üretim prosesinde yüzey aktif madde içeren su preslenmiş lastiklere uygulandıktan sonra, oluşan süzüntü kısmı toplanmakta ve geri devir yaptırılmak sureti ile birkaç kez kullanmaktadır. $\mathrm{Bu}$ sular etkinliğini yitirdiğinde genellikle ya arıtma işlemine alınmaktadır ya da lisanlı firmalara verilerek bertarafi gerçekleştirilmektedir. Endüstride bu atık sular genellikle konvansiyonel koagülasyon (K.K) prosesi uygulanarak arıtılmaktadır.

Bu çalışmada K.K'ya alternatif olarak mikrodalga (MD) ön arıtımı müteakip elektrokoagülasyon prosesinin (EK) uygulandığı kombine prosesin etkinliği incelenmiştir. Kombine proseste atık suya ilk olarak persülfat anyonu (PS) ilave edilerek MD ışımasına maruz bırakılmıştır. MD 1şıması PS'nin aktivasyonunu sağlayarak yüzey aktif maddenin kısmi oksidasyonunu sağlayan $\mathrm{SO}^{\bullet \bullet}$ radikalinin oluşmasını sağlamaktadır. Ön işleme uğramış atık su ikinci aşamada EK'ye tabi tutulmuştur. EK prosesi üç aşamada gerçekleşir [18]: (i) Anotun elektro çözülmesi ile koagülant ve metal hidroksitlerin oluşumu, (ii) Elektrostatik yük nötralizasyonu ile kirleticilerin destabilizasyonu, ve (iii) Flok oluşumu. Demir elektrotlarının kullanıldığı kombine proseste gerçekleşen mekanizmalar Şekil 1'de gösterilmiştir

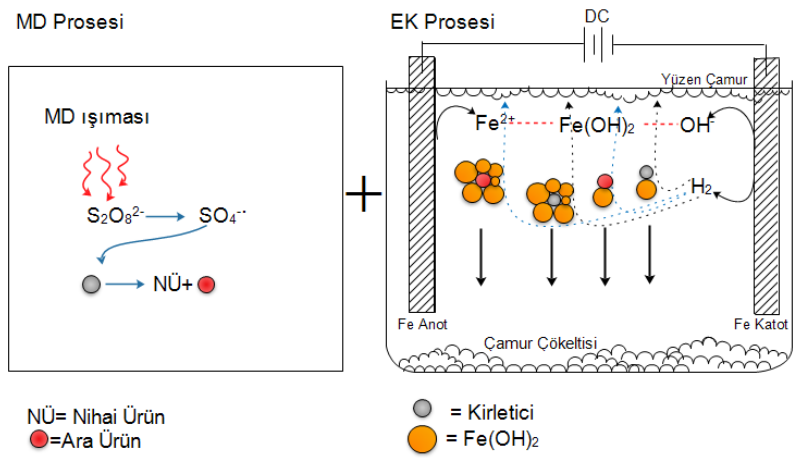

Şekil 1. EK, MD ve MD+EK proseslerinin KOİ giderimi

$\mathrm{Bu}$ çalışmada yüzey aktif madde içeren bu suların konvansiyonel kimyasal koagülasyon K.K prosesi ve mikrodalga ışımasıyla kombine olmuş elektrokoagülasyon prosesi (MD+EK) ile arıtımı karşılaştırılmıştır. Her iki 
proses için Taguchi deneysel tasarımı uygulanarak, maksimum KOİ giderimi için deneysel şartlar optimize edilmiştir. Çalışmanın son aşamasında çok kriterli karar verme süreçlerinden olan PROMETHEE yöntemi kullanılarak bu atık suların arıtımı için en uygun proses belirlenmiştir.

\section{Materyal ve metot}

Denemelerde kullanılan atık su preslenen çĭ̆ lastik hamurunun batırıldığı noniyonik yüzey aktif maddesi içeren tank çıkışından alınmıştır. Atık su 1/5 oranında seyreltildikten sonra kullanılmıştır. Çalışmada kullanılan yüzey aktif madde içerikli atık suyun özellikleri Tablo 1'de belirtilmiştir.

Tablo 1. PROMETHEE analizi alternatif proseslerin kriter değerleri

\begin{tabular}{ccc}
\hline $\begin{array}{c}\text { KOİ } \\
(\mathrm{mg} / \mathrm{L})\end{array}$ & $\mathrm{pH}$ & $\begin{array}{c}\text { İletkenlik } \\
(\mu \mathrm{s} / \mathrm{cm})\end{array}$ \\
\hline $820-1090$ & $7-7.5$ & $750-764$ \\
\hline
\end{tabular}

Çalışmada kullanılan sodyum persülfat $\left(\mathrm{Na}_{2} \mathrm{~S}_{2} \mathrm{O}_{8}, \% 98\right.$ saflıkta), $\mathrm{FeCl}_{3} .7 \mathrm{H}_{2} \mathrm{O}, \mathrm{Na}_{2} \mathrm{SO}_{4}, \mathrm{H}_{2} \mathrm{SO}_{4}$ ve $\mathrm{NaOH}$ Merck'ten temin edilmiştir. Çalışmada kullanılan polielektrolit anyonik karakterde olup ticari ölçekte uygulanmaktadır.

Her bir deney serisinde arıtılan atık su KOİ analizinden önce Hettich Üniversal 320 santrifüj cihazında, 15 dakikada $3500 \mathrm{rpm}$ 'de santrifüjlenmiştir. Alınan üst sıvıda standart 5220-C kapalı refluks titrasyon yöntemine göre KOİ analizi yapılmıştır [19].

\subsection{Metodoloji}

Bu çalışmada iki farklı arıtım prosesi, mikrodalga ışıma ile kombine olmuş elektrokoagülasyon (MD+EK) ve konvansiyonel koagülasyon (KK) incelenmiştir.

MD+EK kombine prosesinde atık suya sülfat radikalinin oluşması için deney tasarım deseninde belirlenmiş dozlarda sodyum persülfat (PS) ilave edildikten sonra belirli sürede belirli güçteki mikrodalga ışımaya maruz bırakılmıştır. Kısmı oksidasyona uğrayan bu atık su ortam sıcaklığına getirildikten sonra demir elektrotlar ile elektrokoagülasyona tabi tutulmuştur. EK sonrası üst sıvıdan alınan numune santrifüjlendikten sonra KOİ analizi yapılmıştır. PS'yi aktive etmek için gerekli MD 1şıması, $2450 \mathrm{MHz}$ frekans ve 700 W'a kadar güce sahip evsel MD firını ile sağlanmıştır (CLATRONIC, Model MWG 786). Elektrokoagülasyon reaktörü polipropilen malzemeden oluşmakta olup $15 * 15 * 20 \mathrm{~cm}$ boyutlarındadır. Demir elektrot plakalarının aktif alanı $35 \mathrm{~cm}^{2}$ dir. Güç kaynağı olarak Mervesan marka 0-30 volt 5 Amper güç ayarlı DC güç kaynağı kullanılmıştır.

Konvansiyonel koagülasyon prosesinde atı suyun kimyasal koagülasyonu VELP Scientifica JLT6 jar testi cihazında yapılmıştır. Deney tasarım deseninde belirlenen dozlarda polielektrolit ve $\mathrm{FeCl}_{3} .7 \mathrm{H}_{2} \mathrm{O}$ ilave edilip, $\mathrm{pH}$ '1 istenen seviyeye getirilmiş atık su, önce hızlı daha sonra yavaş karıştırma işlemine maruz bırakılmıştır. Oluşan floklu yapılar çökeltilmiş ve üst sıvıdan alınan numune santrifüjlendikten sonra KOİ analizi yapılmıştır.

Ham atık su ile proses çıkış suyunun KOİ değerleri dikkate alınarak giderim verimi (\%) hesaplanmıştır. Proseslerin optimum koşullarındaki çamur miktarları APHA standart metot toplam katı madde tayini (1989 S.2-75, GEMS S.22) ile belirlenmiştir. Tayin, çökelen kimyasal çamurun $105^{\circ} \mathrm{C}$ 'de sabit tartıma gelinceye kadar kurutulması ile gerçekleştirilmiştir [19].

\subsection{Optimizasyon çalışması}

Atık suyun en yüksek KOİ giderimini sağlayacak optimum parametre seviye kombinasyonlarının belirlenmesi ve her bir parametrenin KOİ giderimi üzerine etki düzeyinin saptanması amacıyla her iki proses için Taguchi metodolojisi kullanılarak deney tasarımı ve optimizasyon gerçekleştirilmiştir. Her iki prosesin deney tasarımında KOİ giderimi üzerine etkili olan 7 parametre, 2 seviyeli olarak göz önünde bulundurulmuştur. Parametre seviyeleri yapılan ön deneysel çalışmanın sonuçları dikkate alınarak belirlenmiștir. Deneysel tasarımda kullanılan en önemli kavram Sinyal/Gürültü (S/G) oranıdır. S/G oranı kullanılarak sürecin optimize edilmesi ile, proses şartlarının kararlılığ1 sağlanmıştır [20]. Taguchi deneysel tasarımı ve analizleri için Design Expert 10.0.4 yazılımı kullanılmıştır.

\section{3 Çok kriterli karar verme süreci ile en uygun proses seçimi}

Seçimde ulaşılmak istenen hedefi birçok parametrenin belirlediği ve değerlendirilen alternatiflerin her birinin kendine özgü avantajlarının bulunduğu durumlarda karar verme işlemi güç olmaktadır. Bu tür durumlarda çok kriterli karar verme yöntemleri kullanılmaktadır. $\mathrm{Bu}$ yöntemleri kullanmaktaki amaç, alternatif ve kriter sayılarının fazla olduğu durumlarda karar verme mekanizmasını kontrol altında tutabilmek ve karar sonucunu mümkün olduğu kadar kolay ve çabuk elde etmektir [21]. Çok kriterli problemlerin çözümünde kullanılan yöntemlerden olan PROMETHEE yöntemi Brans ve Vincle (1985) tarafından önerilen ve sonrasında geliştirilen bir yöntemdir. Diğer çok kriterli karar verme yöntemleri ile kiyaslandığında PROMETHEE yöntemi, anlaşılabilir metodolojisi ve uygulama kolaylığı açısından öne çıkmaktadır [22]. PROMETHEE yönteminde iki alternatifin ( $a$ ve b) kriterler bakımından karşılaştırılması yapılır ve bir $\mathrm{P}$ fonksiyonu seçilir. Bu fonksiyon iki alternatif arasındaki farkı, 0-1 aralığında değişen bir tercih derecesi içinde ve belirli bir kriter bazında açıklar. $\mathrm{Bu} \mathrm{P}$ fonksiyonu aşağıdaki gibi ifade edilir.

$$
P_{j}(a, b)=\left\{\begin{array}{ll}
0, & f(a) \leq f(b) \\
p[f(a)-f(b)], & f(a)>f(b)
\end{array}\right\}
$$

Alternatifler seçilen tercih fonksiyonu ile kriter bazında ikili olarak karşılaştırılır. PROMETHEE uygulaması bir dizi adımlar takip edilerek gerçekleştirilir [22-24]. Öncelikle her bir kriter için 6 tercih fonksiyonundan (olağan, U-tipi, V-tipi, seviyeli, lineer ve gaussian) uygun olanı seçilir. 
Belirlenen tercih fonksiyonu ile alternatiflerin ikili karşılaştırmaları yapılır ve her alternatif için tercih indeksi Denklem (2) ile belirlenir.

$$
\pi(a, b)=\sum_{j=1}^{n} w_{j} \times P_{j}(a, b)
$$

$\mathrm{n}$, değerlendirme faktörü sayısını ifade ederken wj kriterlerin önem ağırlığını ifade eder.

Tercih indeksleri belirlendikten sonra her alternatifi için pozitif ve negatif akımlar belirlenir (Denklem (3) ve (4)).

$$
\begin{aligned}
& \Phi^{+}(a)=\frac{1}{n-1} \sum_{b \in A} \pi(a, b) \\
& \Phi^{-}(a)=\frac{1}{n-1} \sum_{b \in A} \pi(b, a)
\end{aligned}
$$

Bir alternatifin pozitif akım değeri $\left(\Phi^{+}(a)\right)$ bir diğer alternatifler üzerinde nasıl bir üstünlük sağladığını gösterir ve ne kadar büyük ise o alternatif üstün konuma gelir. Negatif akım değeri ise alternatif üzerinde diğer alternatiflerin üstünlüğünü ifade eder. Dolayısıyla negatif akım $\Phi^{-}(\mathrm{a})$ ne kadar küçük olursa alternatif diğer alternatiflerden o kadar üstün olur.

Hesaplanan pozitif ve negatif akımlar ile PROMETHEE I kismi siralama ve PROMETHEE II net siralama belirlenir. $\mathrm{Bu}$ durumda a alternatifi ile $\mathrm{b}$ alternatifi arasındaki ilişki aşağıdaki şekilde olur.

$$
\begin{gathered}
(a),(b)^{\prime} \text { den üstündür } \\
\left\{\begin{array}{c}
\Phi^{+}(a)>\Phi^{+}(b) \text { ve } \Phi^{-}(a)<\Phi^{-}(b) \\
\Phi^{+}(a)>\Phi^{+}(b) \text { ve } \Phi^{-}(a)=\Phi^{-}(b) \\
\Phi^{+}(a)=\Phi^{+}(b) \text { ve } \Phi^{-}(a)<\Phi^{-}(b)
\end{array}\right\} \\
(a),(b)^{\prime} \text { den farksızdır } \\
\left\{\Phi^{+}(a)=\Phi^{+}(b) \text { ve } \Phi^{-}(a)<\Phi^{-}(b)\right\} \\
(a)(b) \text { karşılaştırılamaz } \\
\left\{\begin{array}{l}
\Phi^{+}(a)>\Phi^{+}(b) \text { ve } \Phi^{-}(a)>\Phi^{-}(b) \\
\Phi^{+}(a)<\Phi^{+}(b) \text { ve } \Phi^{-}(a)<\Phi^{-}(b)
\end{array}\right\}
\end{gathered}
$$

Bu çalışmada PROMETHEE yöntemi yüzey aktif madde içeren atık su arıtımı için önerilen MD+EK ve K.K alternatif proseslerinden en uygun olanı belirlemek için kullanılmıştır. PROMETHEE analizleri Visual PROMETHEE (Academic Edition) yazılımı kullanılarak gerçekleştirilmiştir. Alternatifleri karşılaştırmak için KOİ giderim verimi, çamur oluşumu, işletme maliyeti ve tercih edilebilirlik olarak dört kriter belirlenmiştir. Kriterlerden tercih edilebilirlik kriteri üç karar vericinin görüşü ile beş noktalı sözel veri girişine göre yazılıma sözel olarak girilmiştir ve tüm kriterlere eşit ağırlıklandırma yapılmıştır.

\section{Bulgular ve tartışma}

Ham atık su pH 7'de, 4 amperde (A), 30 dakika boyunca demir elektrotları ile EK prosesine maruz birakıldığında
KOİ'nin \%5.8 oranında giderildiği belirlenmiştir. KOİ gideriminin çok düşük olması üzerine ham atık suya oksidasyon ajanı olarak PS ilavesinden sonra mikrodalga 1şımaya maruz bırakılması ile KOİ giderim veriminin \%10.5 seviyelerine arttığı belirlenmiştir. Yapılan ön çalışmalar ile atıksuyun KOİ gideriminde EK ve MD proseslerinin ayrı ayrı uygulanmasında oldukça etkisiz kaldığ 1 ve her iki prosesin entegre işletimi ile Şekil 2'de gösterildiği gibi KOİ gideriminin \% 52 seviyelerine çıktığı saptanmıştır.

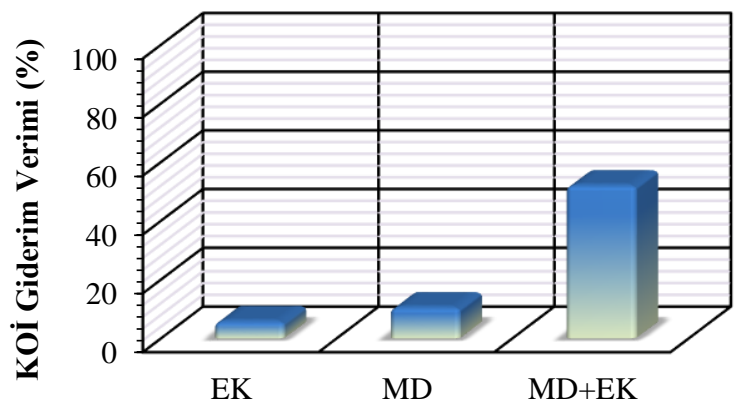

Şekil 2. EK, MD ve MD+EK proseslerinin KOİ giderimi

\subsection{Atık suyun MD ile kombine olmuş EC $(M D+E C)$ prosesi ile arttımının optimizasyonu}

Mikrodalga oksidasyonu ile desteklenmiş elektrokoagülasyon (MD+EK) prosesinde KOİ giderim verimini etkileyen parametreler; MD oksidasyonu için PS dozu (3-10 $\mathrm{g} \mathrm{S}_{2} \mathrm{O}_{8}{ }^{-2}$ anyon/L), MD gücü (406-700 W), MD süresi (10-30 dk) olarak, EK prosesi için ise EK süresi (20$60 \mathrm{dk}$ ), akım (2.5-4 amper), pH (7-9) ve elektrotlar aras1 mesafe (1-2 cm) olarak belirlenmiştir. Her bir parametre için iki seviye dikkate alınmıştır. Seviyeler yapılan ön çalışmalar ile belirlenmiştir. Uygulanan deney tasarım deseni ve cevap parametresi olarak ele alınan KOİ giderim verimleri Tablo 2'de verilmiştir. (MD+EK) prosesini etkileyen parametrelerin optimizasyonu, KOİ giderimini maksimize edecek biçimde çözümlenerek belirlenmiştir.

Modelin uygunluğu ANOVA analizi ile değerlendirilmiştir. MD+EK prosesi için ANOVA analiz sonucu Tablo 3'de verilmiştir. Yüksek F değerleri ve 0.05 den küçük $\mathrm{P}$ değerleri modelin anlamlı olduğunu göstermektedir [25]. F ve P değerleri oluşturulan modelin yanıtı açıklamak için anlamlı olduğunu göstermektedir. $\mathrm{P}$ değerlerine bakıldığında $\mathrm{pH}$ parametresinin KOİ giderimine önemli bir etkisi olmadığı görülmektedir. Diğer tüm parametrelerin $\mathrm{P}$ değerleri 0.05 den küçük olduklarından yanıta önemli derecede etki ettiği söylenebilir.

Optimizasyon sonucunda (MD+EK) prosesinde maksimum KOİ giderimini verecek optimum deneysel koşullar; 30 dakika MD süresi, $700 \mathrm{~W} \mathrm{MD}$ gücü, $10 \mathrm{~g} \mathrm{~S}_{2} \mathrm{O}_{8}{ }^{-}$ 2 anyon/L PS dozu, 60 dakika EK süresi, 4 A akım, pH 9 ve $2 \mathrm{~cm}$ elektrotlar arası mesafe olarak belirlenmiştir. Taguchi deney tasarım modelinin optimum şartlarda öngördüğü KOİ giderim verimi \%64.9 olarak belirlenirken bu şartlarda gerçekleştirilen doğrulama deneyi ile KOİ giderim verimi \%65.2 olarak elde edilmiştir. Modelin ön gördüğü KOİ giderim verimi ile deneysel KOİ giderim veriminin yakın olması modelin anlamlılığını göstermektedir. 
Tablo 2. MD+EK prosesinin Taguchi deneysel tasarımı ve elde edilen KOİ yanıt değerleri

\begin{tabular}{ccccccccc}
\hline No & $\begin{array}{c}\text { PS dozu } \\
\left(\mathrm{g} \mathrm{S}_{2} \mathrm{O}_{8}^{-2} \text { anyon/L) }\right.\end{array}$ & $\begin{array}{c}\text { MD gücü } \\
(\mathrm{W})\end{array}$ & $\begin{array}{c}\text { MD süresi } \\
(\mathrm{dk})\end{array}$ & EK süresi (dk) & $\begin{array}{c}\text { Akım } \\
(\mathrm{A})\end{array}$ & $\mathrm{pH}$ & $\begin{array}{c}\text { Elektrot } \\
\text { arasi mesafe } \\
(\mathrm{cm})\end{array}$ & $\begin{array}{c}\text { KOİ giderim verimi } \\
(\%)\end{array}$ \\
\hline $\mathbf{1}$ & 3 & 406 & 10 & 20 & 2.5 & 7 & 1 & 7.82 \\
$\mathbf{2}$ & 3 & 406 & 10 & 60 & 4 & 9 & 2 & 11.73 \\
$\mathbf{3}$ & 3 & 700 & 30 & 20 & 2.5 & 9 & 2 & 35.09 \\
$\mathbf{4}$ & 3 & 700 & 30 & 60 & 4 & 7 & 1 & 53.69 \\
$\mathbf{5}$ & 10 & 406 & 30 & 20 & 4 & 7 & 2 & 45.10 \\
$\mathbf{6}$ & 10 & 406 & 30 & 60 & 2.5 & 9 & 1 & 48.58 \\
$\mathbf{7}$ & 10 & 700 & 10 & 20 & 4 & 9 & 1 & 50.54 \\
$\mathbf{8}$ & 10 & 700 & 10 & 60 & 2.5 & 7 & 2 & 38.69 \\
\hline
\end{tabular}

Tablo 3. MD+EK prosesinin ANOVA tablosu

\begin{tabular}{cccccc}
\hline Parametre & $\begin{array}{l}\text { Kareler } \\
\text { toplamı }\end{array}$ & SD* & Kareler ortalaması & F değeri & P değeri \\
\hline Model & 2155.40 & 6 & 359.23 & 7081.55 & 0.0091 \\
A-MD süresi & 695.35 & 1 & 695.35 & 13707.43 & 0.0054 \\
B-MD gücü & 524.48 & 1 & 524.48 & 10339.08 & 0.0063 \\
C-PS dozu & 678.53 & 1 & 678.53 & 13375.79 & 0.0055 \\
D-EK süresi & 25.01 & 1 & 25.01 & 493.06 & 0.0287 \\
E-Amper & 119.33 & 1 & 119.33 & 2352.25 & 0.0131 \\
G-Elektrot aralı̆̆1 & 112.70 & 1 & 112.70 & 2221.71 & 0.0135 \\
Hata & 0.051 & 1 & 0.051 & & \\
Toplam & 2155.46 & 7 & & & \\
\hline
\end{tabular}

* F parametresi (pH), KOİ giderimine etkisinin çok az olması nedeniyle hataya dahil edilmiştir. SD: serbestlik derecesi.

KOİ giderim verimi üzerine her bir parametrenin etkisini gösteren Pareto analizi Şekil 3'te verilmiştir. Pareto analizindeki $\mathrm{t}$ değerleri ANOVA üzerindeki $\mathrm{F}$ değerlerinin karekökünü temsil eder. Bonferroni limiti üzerindeki parametreler yanıta yüksek etki ile etki eden parametreleri gösterirken, t limiti ile Bonferroni limiti arasında kalan parametreler etkili olma potansiyeline sahip olan parametreleri gösterir. $\mathrm{t}$ limiti altında kalan parametreler ise yanıta etkisi önemli olmayan parametrelerdir [26, 27]. Şekilden de görüldüğü üzere proseste en önemli parametreler MD süresi, PS dozu ve MD gücü olmuştur. Akım, elektrot aralığı ve EK süresi önemli olma potansiyeline sahip parametrelerdir. $\mathrm{pH}$ parametresi ise yanita etkisi olmayan parametre olarak belirlenmiştir ve çözümlemede hataya dahil edilmiştir.

Literatürde yüzey aktif madde giderimi için mikrodalga ile aktive olmuş persülfat oksidasyonunun ve elektro koagülasyonun ardışık prosesler olarak kullanıldığı bir çalışma bulunmamaktadır. Ancak Bhandari ve Gogate [28] bir anyonik yüzey aktif madde olan sodyum dodesil benzen sülfonat (SDBS)'ın gideriminde çeşitli oksidasyon ajanlarını aktive etmek için mikrodalga 1şımasını kullanmışlardır. Çalışma sonucunda mikrodalganın oksidatif bozunma hızını ve süresini önemli ölçüde arttırdığını gözlemlemişlerdir. Mikrodalga gücünün 280 watt'a kadar artışının önemli ölçüde SDBS gideriminde etkili olduğunu, 280 watt üzeri mikrodalga gücünün giderim verimine oranla ek maliyet getirebileceğini bildirmişlerdir. Aynı zamanda kullanılan üç oksidasyon ajanı, KPS, $\mathrm{NH}_{3} \mathrm{PS}$ ve NaPS kullanımı ile sirasiyla \% 98.3, \% 82.2 ve \% 68.2 bozunma derecesi elde etmişlerdir. Bu çalışmada MD prosesi ile EK prosesi birlikte değerlendirildiğinden MD prosesine etki eden MD süresi ve PS dozu gibi parametreler COD gideriminde EK prosesinden daha etkili olmuştur.

\subsection{Atık Suyun konvansiyonel koagülasyon prosesi ile arıtımının optimizasyonu}

Konvansiyonel koagülasyon prosesi ile yüzey aktif madde içeren atık suyun arıtım prosesinde KOİ gideriminde etkili olan parametreler $\mathrm{pH}(7-9), \mathrm{FeCl}_{3} .7 \mathrm{H}_{2} \mathrm{O}$ dozu (24-48 $\mathrm{mg} / \mathrm{L})$, polielektrolit dozu (8-16 mg/L), hızlı ve yavaş karıştırma hızı (hızlı karıştırma için 50-100, yavaş karıştırma için 10-30 rpm) için ve süreleri (hızlı karıştırma için 1-5, yavaş karıştırma için 5-15 dk) olarak belirlenmiştir. Her bir parametrenin 2 seviyesi dikkate alınmış olup, seviyeler ön denemeler ile belirlenmiştir. 
Tablo 4. K.K prosesinin Taguchi deneysel tasarımı ve elde edilen KOİ yanıt değerleri

\begin{tabular}{|c|c|c|c|c|c|c|c|c|}
\hline No & $\mathrm{pH}$ & $\mathrm{FeCl}_{3} .7 \mathrm{H}_{2} \mathrm{O}(\mathrm{mg} / \mathrm{L})$ & $\begin{array}{c}\text { Polielektrolit } \\
(\mathrm{mg} / \mathrm{L})\end{array}$ & $\begin{array}{l}\text { Hızlı Karıştırma hızı } \\
\text { (rpm) }\end{array}$ & $\begin{array}{c}\text { Yavaş Karıştırma } \\
\text { hızı (rpm) }\end{array}$ & $\begin{array}{l}\text { Hızlı Karıştırma } \\
\text { süresi (dk) }\end{array}$ & $\begin{array}{l}\text { Yavaş karıştırma } \\
\text { süresi }(\mathrm{dk})\end{array}$ & $\begin{array}{l}\text { KOİ giderim verimi } \\
(\%)\end{array}$ \\
\hline 1 & 7 & 24 & 8 & 50 & 10 & 1 & 5 & 53.79 \\
\hline 2 & 7 & 24 & 8 & 100 & 30 & 5 & 15 & 48.92 \\
\hline 3 & 7 & 48 & 16 & 50 & 10 & 5 & 15 & 39.68 \\
\hline 4 & 7 & 48 & 16 & 100 & 30 & 1 & 5 & 48.44 \\
\hline 5 & 9 & 24 & 16 & 50 & 30 & 1 & 15 & 42.12 \\
\hline 6 & 9 & 24 & 16 & 100 & 10 & 5 & 5 & 46.98 \\
\hline 7 & 9 & 48 & 8 & 50 & 30 & 5 & 5 & 19.74 \\
\hline 8 & 9 & 48 & 8 & 100 & 10 & 1 & 15 & 12.93 \\
\hline
\end{tabular}

Tablo 5. K.K prosesinin ANOVA tablosu

\begin{tabular}{cccccc}
\hline Parametre & Kareler toplamı & SD* & Kareler ortalaması & $\begin{array}{c}\text { F } \\
\text { değeri }\end{array}$ & P değeri \\
\hline Model & 1529.52 & 5 & 305.90 & 646.55 & 0.0015 \\
A-pH & 596.27 & 1 & 596.27 & 1260.25 & 0.0008 \\
B-FeCl $7.7 H_{2} \mathrm{O}$ dozu & 630.33 & 1 & 630.33 & 1332.25 & 0.0007 \\
C- Polielektrolit dozu & 218.71 & 1 & 218.71 & 462.25 & 0.0022 \\
E- Y.K hızı (rpm) & 4.26 & 1 & 4.26 & 9.00 & 0.0955 \\
G- Y.K süresi (dk) & 79.96 & 1 & 79.96 & 169.00 & 0.0059 \\
Hata & 0.95 & 2 & 0.47 & &
\end{tabular}

* D (hızlı karıştma hızı) ve F (hızlı karıştırma süresi) parametreleri, KOİ giderimine etkilerinin çok az olması nedeniyle hataya dahil edilmiştir. SD: serbestlik derecesi.

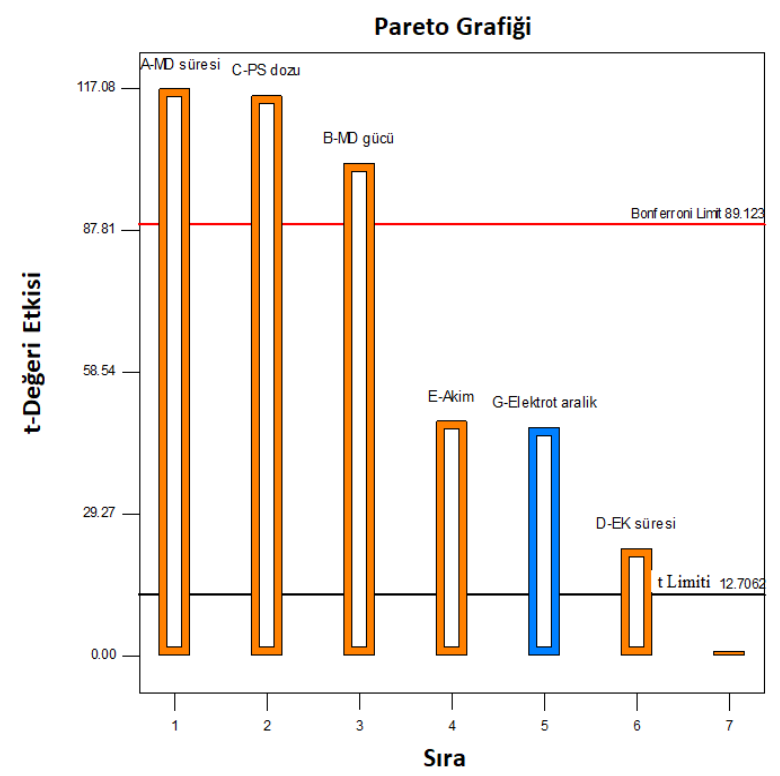

Şekil 3. MD+EK prosesinin Pareto grafiği

Taguchi deney deseni ve cevap parametresi olarak alınan KOİ giderim verimi Tablo 4'te verilmiştir. KOİ giderimini maksimize edecek optimum deneysel koşullar $\mathrm{pH}=7,24$ $\mathrm{mg} / \mathrm{L} \mathrm{FeCl}_{3} .7 \mathrm{H}_{2} \mathrm{O}$ dozu, $8 \mathrm{mg} / \mathrm{L}$ polielektrolit dozu, $50 \mathrm{rpm}$ hızlı karıştırma hızı, 10 rpm yavaş karıştırma hızı, 1 dakika hızlı karıştırma süresi, 5 dakika yavaş karıştırma süresi olarak belirlenmiştir. Modelin öngördüğü KOİ giderim verimi \%53.8 olarak belirlenmiştir. Optimum şartlarda yapılan doğrulama deneyinde KOİ giderim verimi \%54.3 olarak belirlenmiştir. Bu değer deneysel olarak belirlenen en yüksek KOİ giderim verimi olmuştur. K.K prosesi için ANOVA analizi Tablo 5'te verilmiştir. Yüksek F değeri ve 0.05 den küçük $\mathrm{P}$ değeri oluşturulan modelin KOİ giderimi için anlamlı olduğunu göstermektedir. Hızlı karıştırma süresi ve hızı ile yavaş karıştırma hızı parametreleri KOİ giderimine önemli derecede etki etmeyen parametreler oldukları belirlenmiștir.

Konvansiyonel koagülasyon prosesinde KOİ giderimini etkileyen parametrelerin etki düzeyleri, Pareto analizi Şekil 4 'te verilmiştir. Şekilde görüldüğü üzere $\mathrm{FeCl}_{3} .7 \mathrm{H}_{2} \mathrm{O}$ dozu, $\mathrm{pH}$, polielektrolit dozu ve yavaş karıştırma süresi etkili parametreler olurken, yavaş ve hızlı karıștırma hızları ile hızlı karıştırma süresinin KOİ giderimine etkisi önemsiz olan parametreler olduğu belirlenmiştir.

Park vd. [29] çalıșmalarında sentezledikleri flokülant ile konvansiyonel koagülasyon yöntemi kullanılarak atık sudaki anyonik yüzey aktif maddelerin uzaklaştırılması için en uygun koşulları araştırmışlardır. Çalışmanın PARETO analizi incelendiğinde yanıta en çok etki eden parametrelerin 
sıralaması flokülant dozu $>\mathrm{pH}>$ koagülant dozu olarak elde edilmiştir. Hızlı-yavaş karıştırma süresi ve hızı gibi parametrelerin optimizasyon prosesine dahil edilmediği görülmüştür. Bu çalışma sonucunda da incelenen hızl1-yavaş karıştırma süresi ve hızı parametrelerinin yanıta göz ardı edilecek düzeyde az etkisi olduğu, buna karşın koagülant dozu ve $\mathrm{pH}$ parametrelerinin örnek çalışma ile uyumlu olarak yanıta en çok etki eden parametreler olduğu görülmektedir.

Yüzey aktif maddeler içerdikleri heterosiklik atomlar, substitüentlerin sayısı ve pozisyonu, tersiyer dallanma gibi özellikleri nedeniyle birçok kirleticiye göre zor parçalanabilirliktedirler. Bunun yanı sıra hidrofilik grupların elektriksel yükü de flok oluşum mekanizmasında etkilidir. $\mathrm{Bu}$ çalışmada kullanılan sürfaktan içerikli atıksuyun kimyasal yap1 ve elektriksel yük özelliklerinin ileri oksidasyon ve koagülasyonda giderim veriminin düşük kalmasına neden olduğu düşünülmektedir.

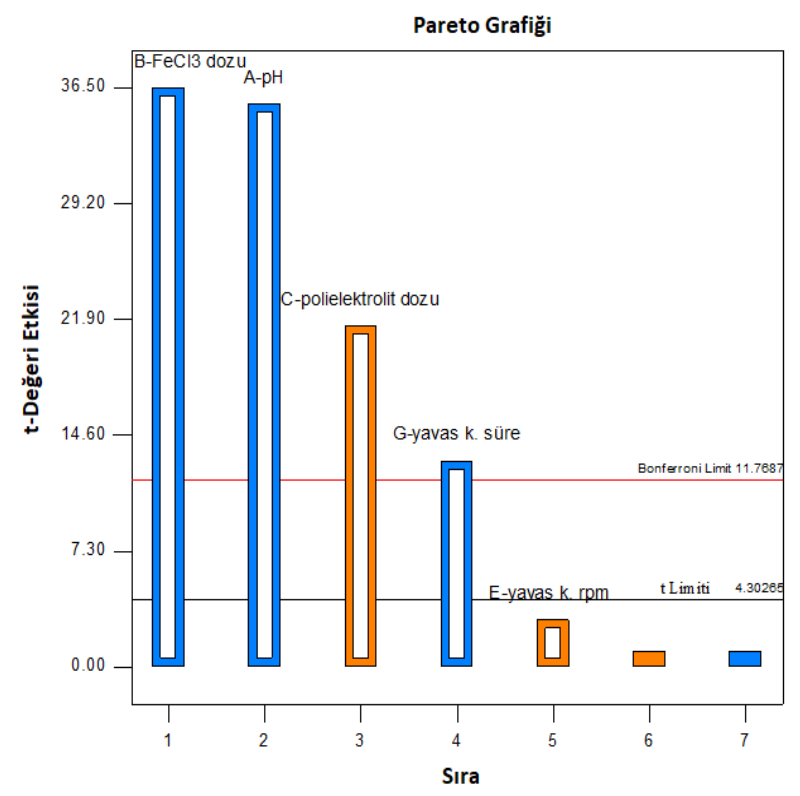

Şekil 4. K.K prosesinin Pareto grafiği

\subsection{Uygun prosesin PROMETHEE yöntemi ile belirlenmesi}

MD+EK ile K.K proseslerinin her ikisi de KOİ giderimi için uygulanabilir proseslerdir. Ancak bir işletme için proses seçiminde pek çok kriter etkilidir. Bu çalışmada iki prosesten en uygun olanının seçiminde, her iki proses için belirlenen optimum şartlar altında işletim maliyeti, üretilen kimyasal çamur miktarı, KOİ giderim verimi ve prosesin tercih edilebilirliği açısından değerlendirilmiştir. İşletim maliyeti için iki prosesteki enerji ve kimyasal tüketimi ( $\mathrm{PS}, \mathrm{H}_{2} \mathrm{SO}_{4}$, $\mathrm{NaOH}$, polielektrolit ve $\left.\mathrm{FeCl}_{3} .7 \mathrm{H}_{2} \mathrm{O}\right)$ ve elektrotların yıpranma tükenme maliyeti dikkate alınmıştır. Enerji tüketiminde birim enerji maliyeti TEDAŞ (Türkiye Elektrik Dağıtım Anonim Şirketi)'ın ev/mesken için enerji tüketim maliyeti baz alınarak $0.074 €$ / kWh olarak kabul edilmiştir. Demir elektrotlarının tüketim maliyeti Gengeç vd. (2012)'de [30] önerilen şekilde Denklem (8)'e göre hesaplanmıştır.

$$
\text { Elektrot tüketimi }\left(\mathrm{kg} / \mathrm{m}^{3}\right)=\frac{i \times t_{E C} \times M_{w}}{Z \times f \times v}
$$

Bu denklemde U hücre voltajı (V), i akım (A), tec çalışma süresi (s), v atık suyun hacmi $\left(\mathrm{m}^{3}\right), \quad \mathrm{Mw}$, elektrot malzemesinin moleküler kütlesi, z aktarılan elektron sayısı (demir elektrot için 2 alınmıştır) ve F, Faraday sabitini (96487 C / mol) ifade eder.

Her iki alternatif prosesin karşılaştırılması için PROMETHEE yöntemi kullanılmıştır ve değerlendirilen kriterlerin aldığı değerler Tablo 6'da sunulmuştur. İşletim maliyeti, çamur miktarı ve KOİ giderim verimi sayısal, tercih edilebilirlik ise sözel ifade olarak alınmıştır. MD+EK prosesinin KOİ verimi K.K prosesinden nispeten yüksek olmasına rağmen K.K prosesinin maliyeti daha düşüktür. $\mathrm{MD}+\mathrm{EK}$ prosesi ile ortaya çıkan çamur miktarı ise $\mathrm{K} . \mathrm{K}$ prosesine göre oldukça düşük bulunmuştur. Tercih edilme kriteri üç karar vericinin sözel verilerinin ortalaması alınarak belirlenmiştir. K.K prosesi daha çok uygulanan ve işletmesi kolay bir proses olduğundan MD+EK prosesinden daha çok tercih edilmiştir.

Tablo 6. PROMETHEE analizi alternatif proseslerin kriter değerleri

\begin{tabular}{ccccc}
\hline Proses & $\begin{array}{c}\text { KOİ } \\
\text { verimi }(\%)\end{array}$ & $\begin{array}{c}\text { İşletme } \\
\text { maliyet } \\
\text { i }(€ / \mathrm{L})\end{array}$ & $\begin{array}{c}\text { Çamur } \\
\text { miktarı } \\
(\mathrm{g} / \mathrm{L})\end{array}$ & $\begin{array}{c}\text { Tercih } \\
\text { edilme }\end{array}$ \\
\hline MD+EK & 66.9 & 1.195 & 6.27 & orta \\
K.K & 54.2 & 0.564 & 19.72 & iyi \\
\hline
\end{tabular}

Visual PROMETHEE yazılımı ile belirlenen alternatiflerin PROMETHEE I (kısmi siralama) ve PROMETHEE II (net sıralama) sonuçları Şekil 5 'te $(\mathrm{a}, \mathrm{b})$ gösterilmiştir.

Alternatiflerin siralamasinda PROMETHEE I ve PROMETHEE II için 0 ve +1 arasında hesaplanan akımlara bakıldığında MD+EK prosesinin pozitif akımı K.K'ya göre +1 e daha yakın olarak bulunmuştur. Negatif akımlarda ise $\mathrm{MD}+\mathrm{EK}$ prosesi 0'a daha yakındır. Bu nedenle MD+EK prosesinin daha tercih edilebilir olduğu söylenebilir. PROMETHEE II ise PROMETHEE I de bulunan akımların farkı ile bulunur ve daha net bir sıralama ifade eder (Şekil 5 (b)). PROMETHEE II'de de görülüğü gibi MD+EK prosesi K.K'ya göre daha tercih edilebilir bir alternatif olmuştur.

GAIA düzlemi PROMETHEE sonuçlarını daha etkileşimli ve görsel olarak ifade eden bir prosedürdür [24]. GAIA düzlemindeki noktalar alternatifleri, vektörler de kriterleri ifade eder. Kırmızı bir vektör ile gösterilen karar vektörü ise en uygun alternatifin seçim yönünü gösterir. $\mathrm{Bu}$ çalışma için GAIA düzlemi Şekil 6'da verilmiştir. Şekilde görüldüğü gibi karar vektörüne en yakın alternatif $\mathrm{MD}+\mathrm{EK}$ alternatifidir. İşletme maliyetini ve çamur oluşumunu gösteren vektörler daha uzun olduklarından karar vektörünü daha çok etkileyen kriterler olmuşlardır. Ayrıştırma gücü az olan kriter vektörlerinin uzunlukları kısa olacaktır [31]. 


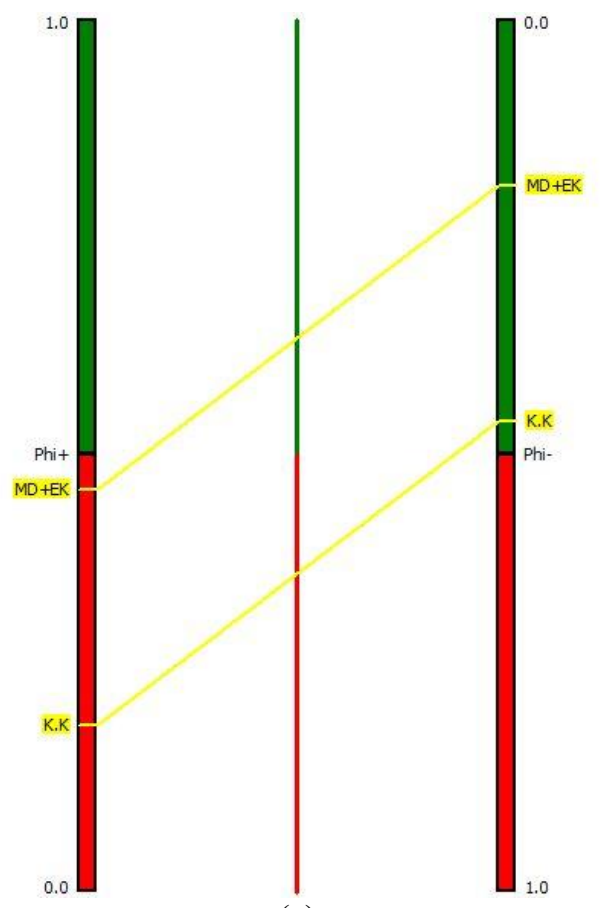

(a)

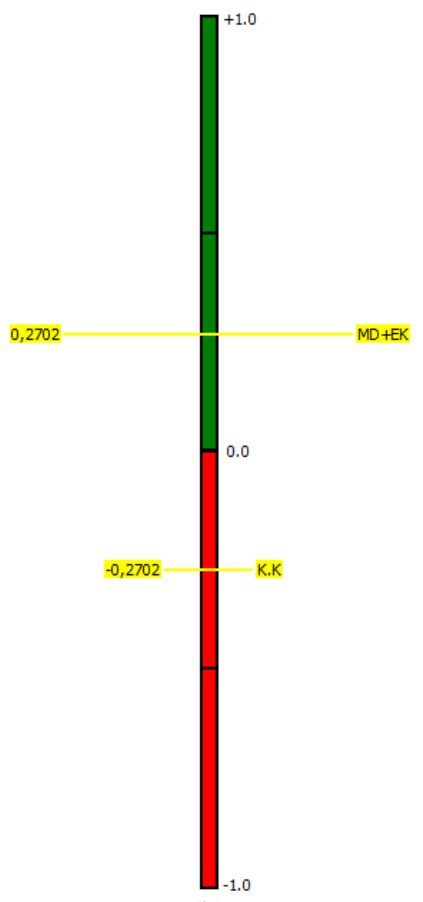

(b)

Şekil 5. Alternatiflerin kısmi sıralaması, PROMETHEE I (a), alternatiflerin net sıralaması, PROMETHEE II (b)

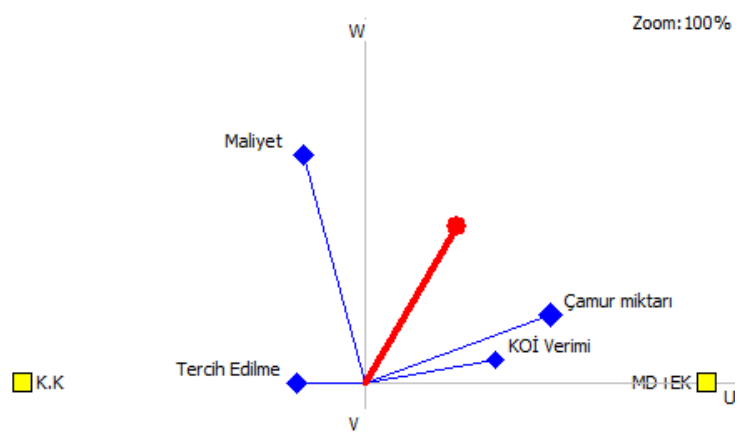

Şekil 6. Alternatiflerin GAIA gösterimi

PROMETHEE analizi içerisinde ki bir diğer analiz PROMETHEE Rainbow analizidir. $\mathrm{Bu}$ analiz ile alternatiflerin sıralamasına pozitif ve negatif yönde etki eden kriterler çubuk dilimler şeklinde net bir biçimde görülebilir. Her bir dilim, bir kriterin katkısı ile alternatifin net akış skoruna orantılıdır. Olumlu (yukarıya doğru) dilimler iyi özelliklere karşılık gelirken, negatif (aşağı doğru) dilimler olumsuz özelliklere karşılık gelmektedir [32]. Bu çalışma için PROMETHEE Rainbow analizi Şekil 7'de gösterildiği gibidir. Şekilde görüldüğü gibi MD+EK prosesini çamur miktarı ve verim kriterleri pozitif yönde etkilerken maliyet ve tercih edilme kriterleri ise negatif yönde etki etmiştir. K.K alternatifini ise tercih edilme ve maliyet kriterleri pozitif yönde etki ederken KOİ verimi ve çamur miktarı kriterleri negatif yönde etki etmiştir. KOİ verimi ve çamur miktarı kriterleri alternatiflerin sıralamasında daha etkili kriterler olduklarından MD+EK prosesi, K.K prosesine göre daha çok tercih edilebilir olmuştur.



Şekil 7. PROMETHEE Rainbow analizi

\section{Sonuçlar}

Yüzey aktif madde endüstrilerde farklı amaçlar için kullanılmaktadır. Araç lastiğin üretim prosesinde lastiği oluşturan preslenmiş çiğ hamurun birbirine yapışmasını engellemek için yüzeyine yüzey aktif madde uygulanmaktadır. Endüstride bu işlem sonucu oluşan süzüntü suyu, önemli bir kirlilik kaynağı oluşturmaktadır. Bu çalışmada yüzey aktif maddesi içeren atık suyun K.K ve MD+EK prosesleri ile arıtımı incelenmiştir. Her iki proses maksimum KOİ giderimini sağlayacak biçimde optimize edilmiştir. Çok kriterli karar verme süreçlerinden olan PROMETHEE yöntemi kullanılarak uygun proses belirlenmiştir. Çalışmada elde edilen sonuçlar aşağıda sunulmuştur;

- K.K için optimum şartlar pH $7.24 \mathrm{mg} / \mathrm{L} \mathrm{FeCl}_{3} .7 \mathrm{H}_{2} \mathrm{O}$ dozu, $8 \mathrm{mg} / \mathrm{L}$ polielektrolit dozu, $50 \mathrm{rpm}$ hızlı 
karıştırma hızı, 10 rpm yavaş karıştırma hızı, 1 dakika hızlı karıştırma süresi, 5 dakika yavaş karıştırma süresi olarak, MD+EK prosesi için optimum şartlar 30 dakika MD süresi, $700 \mathrm{~W}$ MD gücü, $10 \mathrm{~g} \mathrm{~S}_{2} \mathrm{O}_{8}{ }^{-2}$ anyon/L PS dozu, 60 dakika EK süresi, 4 A akım, pH 9 ve $2 \mathrm{~cm}$ elektrotlar arası mesafe olarak belirlenmiştir.

- Belirlenen optimum şartlarda gerçekleştirilen doğrulama deneyleri ile MD+EK prosesinin KOİ giderim verimi \% 65.2 bulunurken K.K prosesinin KOİ giderim verimi 54.3 olarak bulunmuştur.

- Pareto analizi, K.K prosesinde en etkili parametrenin $\mathrm{FeCl} 3.7 \mathrm{H} 2 \mathrm{O}$ dozu olduğunu, MD+EK prosesinde ise MD süresi olduğunu göstermiştir.

- Prosesler KOİ giderim verimi, kimyasal çamur üretimi, işletme maliyeti ve tercih edilebilirlik kriterleri dikkate alınarak PROMETHEE yöntemi ile analiz edildiğinde en uygun prosesin MD+EK prosesi olduğu belirlenmiştir.

- MD+EK prosesinin belirlenmesinde KOİ giderim verimi ve çamur miktarı kriterlerinin seçimi pozitif yönde etkileyerek sonuçta etkili oldukları saptanmıștır.

\section{Çıkar çatışması}

Yazarlar çıkar çatışması olmadığını beyan etmektedir.

Benzerlik oranı (iThenticate): $\% 7$

\section{Kaynaklar}

[1] K. Lawrence, L.K. Wang, Y.T. Yung-Tse Hung, H. Howard, H.H Lo, and C. Constantine Yapijakis, Handbook of Industrial and Hazardous Wastes Treatment. Marcel Dekker Publishing, New York, 2004.

[2] J. Kaleta, and M. Elektorowicz, The removal of anionic surfactants from water in coagulation process, Environmental Technology (United Kingdom), 34(58), 999-1005, 2013. https://doi.org/10.1080/ 09593330.2012.733415

[3] M.J. Scott and M.N. Jones, The biodegradation of surfactants in the environment. Biochimica et Biophysica Acta (BBA) - Biomembranes, 1508(1-2), 235-251, 2000. https://doi.org/10.1016/S03044157(00)00013-7

[4] S.M. Mirbahoush, N. Chaibakhsh and Z. MoradiShoeili, Highly efficient removal of surfactant from industrial effluents using flaxseed mucilage in coagulation/photo-Fenton oxidation process. Chemosphere, 231(51-59), 2019. https://doi.org/ 10.1016/j.chemosphere.2019.05.118

[5] M.A. Aboulhassan, S. Souabi, A. Yaacoubi, and M. Baudu, Removal of surfactant from industrial wastewaters by coagulation flocculation process. International Journal of Environmental Science \& Technology, 3(4), 327-332, 2006. https://doi.org/ 10. 1007/BF03325941

[6] S. Verma, B. Prasad and I.M. Mishra, Pretreatment of petrochemical wastewater by coagulation and flocculation and the sludge characteristics. Journal of Hazardous Materials, 178(1-3), 1055-1064, 2010. https://doi.org/10.1016/j.jhazmat.2010.02.047
[7] A.A. Siyal, M.R. Shamsuddin, A. Low and N.E Rabat, A review on recent developments in the adsorption of surfactants from wastewater. Journal of Environmental Management, 254, 109797, 2020. https://doi.org/ 10.1016/j.jenvman.2019.109797

[8] A.G.L. Moura, V.B. Centurion, D.Y. Okada, F. Motteran, T.P. Delforno, V.M. Oliveira, and M.B.A Varesche, Laundry wastewater and domestic sewage pilot-scale anaerobic treatment: Microbial community resilience regarding sulfide production. Journal of Environmental Management, 251, 109495, 2019. https://doi.org/10.1016/j.jenvman.2019.109495

[9] A. Dhuiib, N. Hamad, and I. Hassairi, Degradation of anionic surfactants by Citrobacter braakii. Process Biochemistry, 38(8), 1245-1250, 2003. https://doi.org/ 10.1016/S0032-9592(02)00322-9

[10] C.V. Faria, T.P. Delforno, D.Y. Okada, and M.B.A. Varesche, Evaluation of anionic surfactant removal by anaerobic degradation of commercial laundry wastewater and domestic sewage. Environmental Technology, 40(8), 988-996, 2019. https://doi.org/ 10.1080/09593330.2017.1414317

[11] J. Huang, L. Zhu, G. Zeng, L. Shi, Y. Shi, K. Yi, and $\mathrm{X}$. Li, Recovery of $\mathrm{Cd}(\mathrm{II})$ and surfactant in permeate from MEUF by foam fractionation with anionicnonionic surfactant mixtures. Colloids and Surfaces A: Physicochemical and Engineering Aspects, 570, 81-88, 2019. https://doi.org/10.1016/j.colsurfa.2019.03.010

[12] B. Mondal, A. Adak, and P. Datta, UV- $\mathrm{H}_{2} \mathrm{O}_{2}$ advanced oxidation of anionic surfactant: reaction kinetics, effects of interfering substances and operating conditions. Environmental Engineering \& Management Journal, 18(6), 1245-1254, 2019. https://doi.org/10.30638/eemj.2019.119

[13] F. Aoudjit, O. Cherifi, and D. Halliche, Simultaneously efficient adsorption and photocatalytic degradation of sodium dodecyl sulfate surfactant by one-pot synthesized $\mathrm{TiO}_{2} /$ layered double hydroxide materials. Separation Science and Technology, 54(7), 1095-1105, 2019. https://doi.org/10.1080/01496395.2018.1527352

[14] R.C. Kaggwa, C.L. Mulalelo, P. Denny, and T.O Okurut, The impact of alum discharges on a natural tropical wetland in Uganda. Water Research, 35(3) 795-807, 2001. https://doi.org/10.1016/S0043-1354 (00)00301-8

[15] C. Zhang, K.T. Valsaraj, W.D. Constant, and D. Roy, Aerobic biodegradation kinetics of four anionic and nonionic surfactants at sub- and supra-critical micelle concentrations (CMCs). Water Research, 33(1), 115124, 1999. https://doi.org/10.1016/S0043-1354(98) 00 $170-5$

[16] M.I. Bautista-Toledo, J. Rivera-Utrilla, J. D. MéndezDíaz, M. Sánchez-Polo, and F. Carrasco-Marín, Removal of the surfactant sodium dodecylbenzenesulfonate from water by processes based on adsorption/bioadsorption and biodegradation. Journal of Colloid and Interface Science, 418, 113-119, 2014. https://doi.org/10.1016/j.jcis.2013.12.001 
[17] H. Hidaka, T. Oyama, T. Horiuchi, T. Koike, and N. Serpone, Photo-induced oxidative synergistic degradation of mixed anionic/cationic surfactant systems in aqueous dispersions. A detailed study of the DBS/HTAB system. Applied Catalysis B: Environmental, 99(3-4), 485-489, 2010. https://doi.org/ 10.1016/j.apcatb.2010.06.041

[18] S. Sharma, and H. Simsek, Treatment of canola-oil refinery effluent using electrochemical methods: A comparison between combined electrocoagulation + electrooxidation and electrochemical peroxidation methods. Chemosphere, 221, 630-639, 2019. https://doi.org/10.1016/j.chemosphere.2019.01.066

[19] APHA, Standard methods for the examination of water and wastewater. 21st edn. Washington, DC: American Public Health Association, 2005.

[20] P.J. Ross, Taguchi Techniques for Quality Engineering. McGraw Hill Internatioanal, New York, 1996.

[21] F. Urfalığlu, and T. Genç, Çok kriterli karar verme teknikleri ile Türkiye'nin ekonomik performansının avrupa birliği üye ülkeleri ile karşılaştırılması. Marmara Üniversitesi İktisadi ve İdari Bilimler Dergisi, 35, 329-360, 2015. https://doi.org/ 10.14780/iibdergi.201324469

[22] M. Gul, E. Celik, A. Taskin Gumus, and A.F. Guneri, A fuzzy logic based promethee method for material selection problems. Beni-Suef University Journal of Basic and Applied Sciences, 7(1), 68-79, 2018. https://doi.org/10.1016/j.bjbas.2017.07.002

[23] J.P. Brans, P.H. Vincke, and B. Mareschal, How to select and how to rank projects: the promethee method. European Journal of Operational Research, 24(2), 228238, 1986. https://doi.org/10.1016/0377-2217(86) 90044-5

[24] M. Behzadian, R.B Kazemzadeh, A. Albadvi, and M. Aghdasi, PROMETHEE: a comprehensive literature review on methodologies and applications. European Journal of Operational Research, 200(1), 198-215, 2010. https://doi.org/10.1016/j.ejor.2009.01.021

[25] J. Behin, N. Farhadian, M. Ahmadi, and M. Parvizi, Ozone assisted electrocoagulation in a rectangular internal-loop airlift reactor: Application to decolorization of acid dye. Journal of Water Process Engineering, 8, 171-178, 2015. https://doi.org/10.1016/ j.jwpe.2015.10.003

[26] M. Asem, W.M.F.W. Nawawi, and D.N. Jimat, Evaluation of water absorption of polyvinyl alcoholstarch biocomposite reinforced with sugarcane bagasse nanofibre: optimization using two-level factorial design. IOP Conference Series: Materials Science and Engineering, 368, 012005, 2018. https://doi.org/ 10.1088/1757-899X/368/1/012005

[27] M.M Abdulredha, S.A. Hussain, and L.C. Abdullah, Separation emulsion via non-ionic surfactant: an optimization. Processes, 7(6), 382, 2019. https://doi.org/10.3390/pr7060382

[28] P.S. Bhandari, \& P.R. Gogate, Microwave assisted persulfate induced degradation of sodium dodecyl benzene sulfonate. Korean Journal of Chemical Engineering, 36(12), 200-2007, 2019. https://doi.org/ 10.1007/s11814-019-0390-Z

[29] B.H. Park, S. Kim, A.Y. Seo, \& T.G. Lee, Evaluation of optimal conditions for anionic surfactant removal in wastewater. Chemosphere, 263, 128174, 2021. https:// doi.org/10.1016/j.chemosphere.2020.128174

[30] E. Gengec, M. Kobya, E. Demirbas, A. Akyol, and K. Oktor, Optimization of baker's yeast wastewater using response surface methodology by electrocoagulation. Desalination, 286, 200-209, 2012. https://doi.org/ 10.1016/j.desal.2011.11.023

[31] G. Tuzkaya, B. Gülsün, C. Kahraman, and D. Özgen, an İntegrated fuzzy multi-criteria decision making methodology for material handling equipment selection problem and an application. Expert Systems with Applications, 37(4), 2853-2863, 2010. https://doi.org/ 10.1016/j.eswa.2009.09.004

[32] R.J. Li, Fuzzy method in group decision making. Computers \& Mathematics with Applications, 38 (1), 91-101, 1999. https://doi.org/10.1016/S0898-1221 (99) 00172-8 